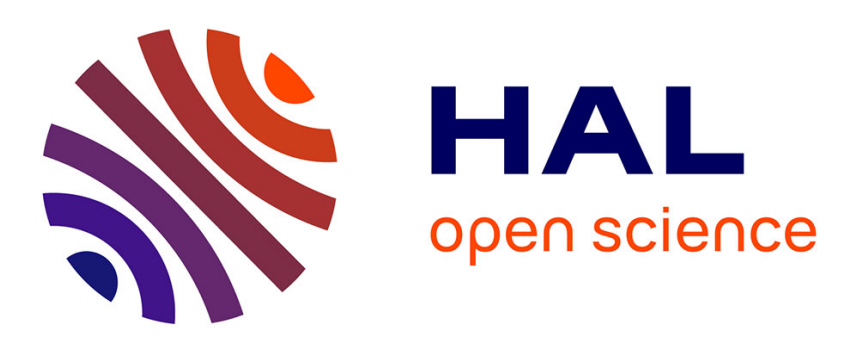

\title{
Joint angle estimation with accelerometers for dynamic postural analysis
}

\author{
Jianting Ma, Haissam Kharboutly, Abderraouf Benali, Faïz Ben Amar, \\ Mourad Bouzit
}

\section{- To cite this version:}

Jianting Ma, Haissam Kharboutly, Abderraouf Benali, Faïz Ben Amar, Mourad Bouzit. Joint angle estimation with accelerometers for dynamic postural analysis. Journal of Biomechanics, 2015, 48 (13), pp.3616-3624. 10.1016/j.jbiomech.2015.08.008 . hal-03178040

\section{HAL Id: hal-03178040 \\ https://hal.science/hal-03178040}

Submitted on 24 Mar 2021

HAL is a multi-disciplinary open access archive for the deposit and dissemination of scientific research documents, whether they are published or not. The documents may come from teaching and research institutions in France or abroad, or from public or private research centers.
L'archive ouverte pluridisciplinaire HAL, est destinée au dépôt et à la diffusion de documents scientifiques de niveau recherche, publiés ou non, émanant des établissements d'enseignement et de recherche français ou étrangers, des laboratoires publics ou privés. 


\section{Joint Angle Estimation with Accelerometers for Dynamic Postural Analysis}

Jianting MA, Haissam KHARBOUTLY, Abderraouf BENALI, Faïz BEN AMAR, Mourad BOUZIT

Jianting MA is with the Institute for Intelligent Systems and Robotics (ISIR), University Pierre \& Marie Curie (UPMC)

Address: 4 Place Jussieu, 75005 Paris, France

Phone: (33) 0144277061

Email: jianting.ma@assistmov.com

Haissam KHARBOUTLY is with the Institute for Intelligent Systems and Robotics (ISIR), University Pierre \& Marie Curie (UPMC)

Address: 4 Place Jussieu, 75005 Paris, France

Phone: (33) 0144277061

Email: haissam.kharboutly@assistmov.com

Abderraouf BENALI is with the INSA centre Val de Loire, de Bourges, Univ. Orléans, PRISME, EA 4229,

Address: 88, Boulevard Lahitolle, 18020 Bourges, France

Phone: (33) 0248484081

Email: abderraouf.benali@ensi-bourges.fr

Faïz BEN AMAR is with the Institute for Intelligent Systems and Robotics (ISIR), University Pierre \& Marie Curie (UPMC)

Address: 4 Place Jussieu, 75005 Paris, France

Phone: (33) 0144276342

Email: amar@isir.upmc.fr

Corresponding Author:

Mourad BOUZIT was with the University Pierre \& Marie Curie. He is now with the Company ASSISTMOV SAS,

Address: 4 Rue Pierre Fontaine, Pépinière Génopole Entreprise, 91058 Evry, France

Phone: (33) 0144277061

Email: $\underline{\text { mourad.bouzit@assistmov.com }}$

\section{Word count (Introduction through Discussion): 3601 words}




\section{Abstract}

This paper presents a new accelerometer based method for estimating the posture of a subject standing on a dynamic perturbation platform. The induced perturbation is used to study the control mechanisms as well as the balance requirements that regulate the upright standing. These perturbations are translated into different intensity levels of speed and acceleration along longitudinal and lateral directions of motion.

In our method, the human posture is modeled by a tridimensional, three-segment inverted pendulum which simultaneously takes into account both the anterior-posterior and medio-lateral strategies of hip and ankle. Four tri-axial accelerometers are used her, one accelerometer is placed on the platform, and the other three are attached to a human subject.

Based on the results, the joint angle estimated compare closely to measurements from magnetic encoders placed on an articulated arm joint. The results were also comparable to those found when using a high-end optical motion capture system coupled with advanced biomechanical simulation software. This paper presents the comparisons of our accelerometer-based method with encoder and optical marker based method of the estimated joint angles under different dynamics perturbations.

Index Terms - Joint estimation, Postural disturbance, Inverted pendulum, Tri-axial accelerometer, Omnidirectional mobile platform.

\section{INTRODUCTION}

The balance disorder is a major health problem that has attracted a great deal of research in recent decades. A person who suffers from these disorders may fall, and get injured. The result could reduce autonomy in daily activities leading to potential isolation or withdrawal. These injuries are worse for the elderly, where according to several studies $36 \%$ of people aged 75 have postural instability (Faucher et al., 2000; Halpern et al., 2005; Pereira, 2006). A clinical examination is the only way to determine 
the cause of postural disorder. This evaluation is a delicate process because of the large number of pathologies related to the involved systems in maintaining equilibrium. Hence by means of dynamic perturbation platform one can investigate the control mechanisms as well as the balance requirements in the regulation of upright standing. In order to conduct such evaluation in the laboratory, we developed a new specifically designed omnidirectional mobile platform for balance analysis (described in section III.A).

Few studies have used mobile platforms to generate dynamic perturbations coupled to a force plate and accelerometers. The benefit of the omnidirectional mobile platform is to generate perturbations in the longitudinal and lateral directions (sagittal and frontal planes), the accelerometers are used to better analyze the human equilibrium strategy adopted by estimating ankle, knee and hip joint angles.

Several approaches have been used to estimate joint angles from the numerical integration of acceleration measurements. Willemsen et al. (1990) estimated the joint angles with eight uniaxial accelerometers installed on two plastic beams secured to the thigh and shank. With a similar device, Heyn et al. (1996) carried out estimation by integrating the gyroscopes signals and adding a compensated angle estimated in a stationary case by the accelerometers. The accuracy of their estimates is acceptable; however, the device configuration was cumbersome. Williamson and Andrews (2001) also used the integration of the gyroscopes signals with accelerometers signals as compensator to estimate the knee angle. Dejnabadi et al. (2005) developed a new approach for accurate measurement of uniaxial joint angles based on a combination of accelerometers and gyroscopes. O'Donovan et al. (2007) used two tri-axial accelerometers, two gyroscopes and two magnetometers to measure the ankle angle. The performance of these techniques was only investigated in the static condition. Liu et al. (2009) used a double-sensor difference based algorithm for analyzing human segment rotational angles in two directions for segmental orientation analysis in the three-dimensional. Takeda (2009) estimated the joint angles of each lower limb segment with two tri-axial accelerometers and six gyroscopes. Fong and Chan (2010) carried out a complete survey of measurement methods based on accelerometers and 
gyroscopes. Tadano et al. (2013) estimated the joint angles of both lower limb segments with seven sensor units consisting of a tri-axial accelerometer and a gyroscope and quaternion calculations.

In this article we will present a new method named: Accelerometer Posture Capture $(A P C A P)$. This method is for estimating the joint angles of human body modeled by a four rigid segments serially connected by three joints, hip, knee and ankle. The knee joint allows a movement in the sagittal plane, while the hip and the ankle joints allow movements in the sagittal and frontal planes. The accelerometers are placed on each segment and will enable the estimation of the joint angles. These measurements are used to identify the 3D balance strategies adopted by a subject (hip or ankle strategy) which is one of our contributions in the postural stability analysis on mobile platforms. Indeed, to our best knowledge, few studies have estimated more joints in 3D using only accelerometers.

The paper is organized as follows. In the next section, we will present the $A P C A P$ method for estimating the 3D joint angles of a human model in sagittal and frontal planes. In the third section, we will present the experimental results applied to a four segments articulated mechanical system, a custom-made mechanical arm for planar validation. In the fourth section, we will show the experimental results on a healthy subject obtained with three different estimation methods. We will summarize our results in the discussion and conclusion.

\section{ESTIMATION OF JOINT ANGLES}

In this section, we will describe the algorithm of the proposed method to calculate joint angles of a human subject standing on a mobile platform and subjected to translational dynamic perturbation.

In Figure 1, a human subject is represented by a four segments model containing the foot, shank, thigh, and trunk. The feet are considered to be rigidly fixed on the platform. The ankle and hip joints are represented by a double rotational link allowing the rotation in the sagittal and frontal planes. The knee joint is made up of a single longitudinal rotational link. The translational perturbation created by the platform acts on the feet with accelerations $a_{x}^{p}, a_{y}^{p}$ and $a_{z}^{p}$ measured by an accelerometer on the 
platform. The other three accelerometers are placed on the segments representing the shank, thigh, and trunk. The distance between the accelerometer and the corresponding joint that it measures is denoted by $d_{i}(i=1,2,3)$. Each accelerometer measures the value $a_{x i}^{m}, a_{y i}^{m}$ and $a_{z i}^{m}$ relative to its own frame. The $a_{x i}^{m}$ direction is always parallels to the sagittal plan while the $a_{y i}^{m}$ direction is the anatomical vertical axis. We noted the linear acceleration relative to global coordinates $(\mathrm{X}, \mathrm{Y}, \mathrm{Z})$ at each measured joint as $a_{x i}^{d}, a_{y i}^{d}$ and $a_{z i}^{d}$. Note that in the disturbance case, the subject's segments are inclined longitudinally and laterally. Figure 1b shows a segment inclination with a longitudinal angle $\alpha_{i}$ and a lateral angle $\beta_{i}$ relative to vertical planes. Note that the rotation angle around each segment of the subject is neglected, given that the dynamic disturbance is transnational only. The dynamic coupling of the momentum is then negligible.

The length of the shank and thigh are respectively denoted by $l_{1}, l_{2}$. The length of the trunk does not play a role in the calculation. If we note the gravitational acceleration $g$, the measurement $a_{x i}^{m}$ can be represented by the components of $\left(\operatorname{s} \alpha_{i} \equiv \sin \alpha_{i}, c \alpha_{i} \equiv \cos \alpha_{i}, s \beta_{i} \equiv \sin \beta_{i}, c \beta_{i} \equiv \cos \beta_{i}\right)$ :

- tangential acceleration: $d_{i} \ddot{\alpha}_{i} c \beta_{i}$

- gravitational acceleration: $-g s \alpha_{i}$

- linear acceleration at the measured joint: $a_{x i}^{d} c \alpha_{i}-a_{y i}^{d} s \alpha_{i}$

The measurement $a_{z i}^{m}$ can be represented by the components of:

- tangential acceleration: $-d_{i} \ddot{\beta}_{i}$

- gravitational acceleration: $g s \beta_{i} c \alpha_{i}$

- linear acceleration at the measured joint: $a_{x i}^{d} s \beta_{i} s \alpha_{i}+a_{y i}^{d} s \beta_{i} c \alpha_{i}+a_{z i}^{d} c \beta_{i}$

The measured accelerations $a_{x i}^{m}$ and $a_{z i}^{m}$ are expressed in matrix form as: 


$$
\left(\begin{array}{c}
a_{x i}^{m} \\
a_{z i}^{m}
\end{array}\right)=\left(\begin{array}{c}
d_{i} \ddot{\alpha}_{i} c \beta_{i}-g s \alpha_{i}+a_{x i}^{d} c \alpha_{i}-a_{y i}^{d} s \alpha_{i} \\
-d_{i} \ddot{\beta}_{i}+g s \beta_{i} c \alpha_{i}+a_{x i}^{d} s \beta_{i} s \alpha_{i}+a_{y i}^{d} s \beta_{i} c \alpha_{i}+a_{z i}^{d} c \beta_{i}
\end{array}\right)
$$

with

$$
\left(\begin{array}{c}
a_{x i}^{d} \\
a_{y i}^{d} \\
a_{z i}^{d}
\end{array}\right)=\left(\begin{array}{c}
l_{i^{\prime}} \ddot{\alpha}_{i^{\prime}} c \alpha_{i^{\prime}} c \beta_{i^{\prime}}-l_{i^{\prime}} \ddot{\beta}_{i^{\prime}} s \alpha_{i^{\prime}} s \beta_{i^{\prime}}+a_{x i^{\prime}}^{d} \\
-l_{i^{\prime}} \ddot{\alpha}_{i^{\prime}} s \alpha_{i^{\prime}} c \beta_{i^{\prime}}-l_{i^{\prime}} \ddot{\beta}_{i^{\prime}} c \alpha_{i^{\prime}} s \beta_{i^{\prime}}+a_{y i^{\prime}}^{d} \\
-l_{i^{\prime} \ddot{\beta}_{i^{\prime}} c \beta_{i^{\prime}}+a_{z i^{\prime}}^{d}}
\end{array}\right),\left(\begin{array}{c}
a_{x 1}^{d} \\
a_{y 1}^{d} \\
a_{z 1}^{d}
\end{array}\right)=\left(\begin{array}{c}
a_{x}^{p} \\
a_{y}^{p} \\
a_{z}^{p}
\end{array}\right) \text { and } i^{\prime} \equiv i-1
$$

In the discrete time domain, equation (1) can be expressed by replacing the continuous derivatives by their approximations as equation (2) where: $k=2 \ldots N-1$ and $N$ is the number of samplings, $T$ is the sampling period.

$$
\left(\begin{array}{c}
a_{x i, k}^{m} \\
a_{z i, k}^{m}
\end{array}\right)=\left(\begin{array}{c}
d_{i} c \beta_{i, k} \frac{\alpha_{i, k+1}-2 \alpha_{i, k}+\alpha_{i, k-1}}{T^{2}}-\left(a_{y i, k}^{d}+g\right) \frac{s \alpha_{i, k}}{\alpha_{i, k}} \alpha_{i, k}+a_{x i, k}^{d} c \alpha_{i, k} \\
-d_{i} \frac{\beta_{i, k+1}-2 \beta_{i, k}+\beta_{i, k-1}}{T^{2}}+\left(a_{x i, k}^{d} s \alpha_{i, k}+a_{y i, k}^{d} c \alpha_{i, k}+g c \alpha_{i, k}\right) \frac{s \beta_{i, k}}{\beta_{i, k}} \beta_{i, k}+a_{z i, k}^{d} c \beta_{i, k}
\end{array}\right)
$$

with

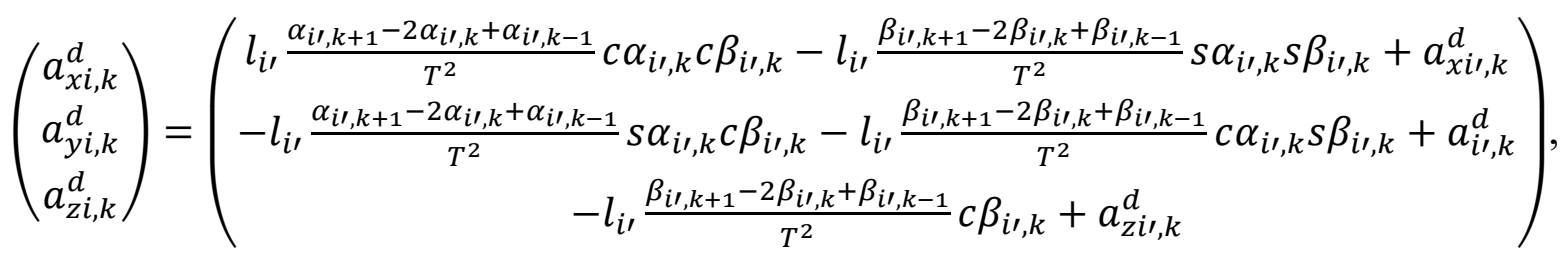

$$
\begin{aligned}
& \left(\begin{array}{l}
a_{x 1, k}^{d} \\
a_{y 1, k}^{d} \\
a_{z 1, k}^{d}
\end{array}\right)=\left(\begin{array}{c}
a_{x, k}^{p} \\
a_{y, k}^{p} \\
a_{z, k}^{p}
\end{array}\right) \text { and } i^{\prime} \equiv i-1
\end{aligned}
$$

Equation (2) can also be written in compact form (3):

$$
\left(\begin{array}{c}
a_{x i, k}^{m} \\
a_{z i, k}^{m}
\end{array}\right)=\left(\begin{array}{l}
B_{s i, k} \alpha_{i, k-1}+B_{s i, k} \alpha_{i, k+1}+C_{s i, k} \alpha_{i, k}+a_{x i, k}^{d} c \alpha_{i, k} \\
B_{f i, k} \beta_{i, k-1}+B_{f i, k} \beta_{i, k+1}+C_{f i, k} \beta_{i, k}+a_{z i, k}^{d} c \beta_{i, k}
\end{array}\right)
$$

with 


$$
\left(\begin{array}{c}
B_{s i, k} \\
C_{s i, k} \\
B_{f i, k} \\
C_{f i, k}
\end{array}\right)=\left(\begin{array}{c}
\frac{d_{i}}{T^{2}} c \beta_{i, k} \\
-2 \frac{d_{i}}{T^{2}} c \beta_{i, k}-\left(a_{y i, k}^{d}+g\right) \\
-\frac{d_{i}}{T^{2}} \\
2 \frac{d_{i}}{T^{2}}+\left(a_{x i, k}^{d} s \alpha_{i, k}+a_{y i, k}^{d} c \alpha_{i, k}+g c \alpha_{i, k}\right)
\end{array}\right)
$$

since $\frac{s \alpha_{i, k}}{\alpha_{i, k}} \approx \frac{s \beta_{i, k}}{\beta_{i, k}} \approx 1$

When $k=2 \ldots N-1$, equation (3) is expressed in a matrix form according to equation (4):

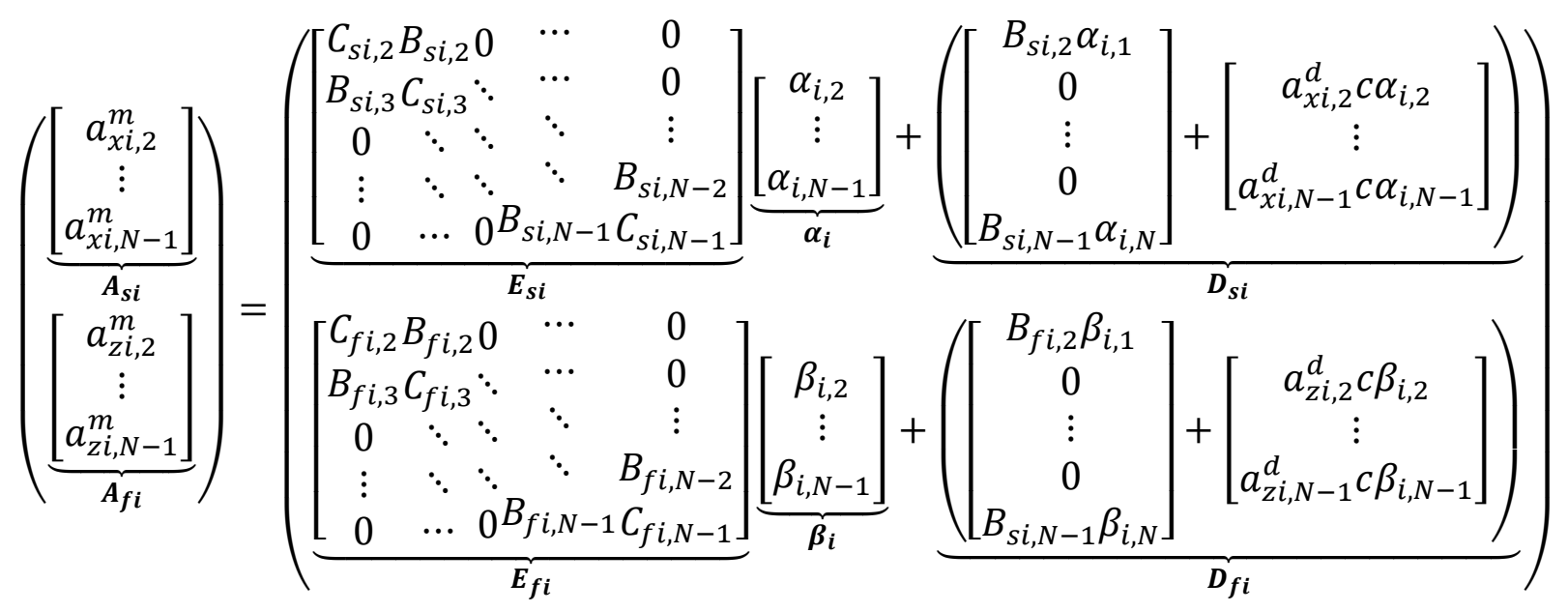

which can be written over in the form of equation (5) using the algorithm of Thomas (1949):

$$
\underbrace{\left(\begin{array}{c}
E_{s i} \\
E_{f i}
\end{array}\right)}_{E_{i}} \underbrace{\left(\begin{array}{c}
\alpha_{i} \\
\beta_{i}
\end{array}\right)}_{\theta_{i}}=\underbrace{\left(\begin{array}{c}
A_{s i} \\
A_{f i}
\end{array}\right)}_{A_{i}}-\underbrace{\left(\begin{array}{c}
D_{s i} \\
D_{f i}
\end{array}\right)}_{D_{i}}
$$

The estimation of the vector $\boldsymbol{\theta}_{\boldsymbol{i}}$ is determined by a modified iterative algorithm proposed by Caroselli et al. (2013). To use this algorithm, the outputs of accelerometers $\boldsymbol{A}_{\boldsymbol{i}}$ are divided by a series of time windows and are considered to be the values entered into the equation (5). There are $N$ continuous samplings in each time window. The second sampling of a time window is the first sampling of the next window. The initialization of our modified algorithm is performed from the quasi-static position just before the disturbance. Thus, for the first cycle of the iterative calculation, the values $\alpha_{i, k}$ and $\beta_{i, k}$ in the vectors $\boldsymbol{E}_{\boldsymbol{i}}$ and $\boldsymbol{D}_{\boldsymbol{i}}$ as well as the values $\alpha_{i, 1}, \alpha_{i, N}, \beta_{i, 1}$ and $\beta_{i, N}$ in the vector $\boldsymbol{D}_{\boldsymbol{i}}$ are given by the quasi-static longitudinal estimate $\alpha_{i}^{q}$ and lateral estimate $\beta_{i}^{q}$ : 


$$
\underbrace{\left(\begin{array}{c}
\alpha_{i}^{q} \\
\beta_{i}^{q}
\end{array}\right)}_{\boldsymbol{\theta}_{i}^{q}}=\left(\begin{array}{c}
\operatorname{arcs} \frac{a_{x i}^{q}}{g} \\
\operatorname{arcs} \frac{a_{z i}^{q}}{-g * c \alpha_{i}^{q}}
\end{array}\right)
$$

with $a_{x i}^{q}$ and $a_{z i}^{q}$ are the measurements from the accelerometers when the subject is quasi-static just before the disturbance.

The estimated joint angles are found at the end of calculation by:

$$
\theta_{i}^{e}=\theta_{i}-\theta_{i-1}
$$

with $\boldsymbol{\theta}_{\mathbf{0}}=0, \boldsymbol{\theta}_{1}^{\boldsymbol{e}}$ is ankle angle, $\boldsymbol{\theta}_{2}^{\boldsymbol{e}}$ is knee angle, $\boldsymbol{\theta}_{3}^{\boldsymbol{e}}$ is hip angle.

We consider that all joint angles are zero at the beginning of the perturbation. Then we have the following joint angles:

$$
\theta_{i}^{0}=\theta_{i}^{e}-\left(\theta_{i}^{q}-\theta_{i-1}^{q}\right)
$$

with $\boldsymbol{\theta}_{\mathbf{0}}^{\boldsymbol{q}}=0, \boldsymbol{\theta}_{\boldsymbol{i}}^{\mathbf{0}}$ is the estimation in case the joint angles are disclaimed at the beginning of the perturbation.

This initial consideration $\left(\boldsymbol{\theta}_{\mathbf{0}}^{\boldsymbol{q}}=0\right)$ is compatible with the applications of the analysis of the dynamic equilibrium since it is only interested in changes in joint angles. In this case, the initial posture is not critical.

\section{EVALUATION ON AN ARTICULATED ARM}

In this part, we propose to experimentally validate the developed method on an articulated arm mounted on a mobile platform. Both mechanical systems will be briefly described in the following sections. Beyond the APCAP method, a geometric method MOCAP (Motion Capture) is also tested and compared. The MOCAP method uses geometric equations and the data recorded by a motion capture system to determine the joint angles. The details of the geometrical method are well known in the literature (Craig, 1989) and will not be presented here. 


\section{A. Articulated arm and mobile platform}

The test system consists of an articulated arm equipped with multiple sensors and mounted on an omnidirectional mobile perturbation platform see Fig. 2.

The dynamic perturbation platform, named IsiSkate (ASSISTMOV SAS, Paris, France), is an omnidirectional mobile robot. The new platform is specifically designed for balance analysis (Ma et al., 2014). It is able to create different types of perturbations (translations, rotations) by controlling various acceleration and speed profiles. It is particularly used to reproduce acceleration and deceleration in public transport to study the stability of a subject.

The platform has four motorized wheel modules allowing sufficient and configurable mobility. With this platform, it is possible to choose the desired curvature of the trajectory given its kinematic configuration. It is capable to handle human weight of $120 \mathrm{~kg}$ while moving at maximum acceleration of $6 \mathrm{~m} / \mathrm{s}^{2}$ in the longitudinal or lateral directions. It is equipped with several force sensors to measure the displacement of the center of pressure, of a subject standing on it, in real time with an accuracy of $0.1 \mathrm{~mm}$ and sampling rate of $100 \mathrm{~Hz}$.

The articulated arm is a mechanical system specially designed for this study (Fig. 2). It is built with four segmented inverse pendulum with three degrees of freedom to replicate the joints of the ankle, knee, and hip. Their lengths represent the foot, shank, thigh, and trunk of a person. The lengths of these segments are $l_{1}=0.41 \mathrm{~m}$ for the shank and $l_{2}=0.40 \mathrm{~m}$ for the thigh. The length of the foot and trunk

does not play a role in the calculation. These lengths are chosen proportional to the size of a human of $1.65 \mathrm{~m}$ according to the anthropomorphic relationship given by Drillis and Contini (1966). The chosen arm length of $1.65 \mathrm{~m}$ corresponds to the height of our subject in the next experiment. A pair of springs is mounted with its two ends fixed on two related segments to maintain the arm in the vertical position without interfering with its inclination in a vertical plane. Indeed, the position of the springs is adjusted to allow small joint rotations under the perturbation of the platform comparable to those of a human. 
The rotation angle of each joint is measured by a magnetic encoder with a resolution of $\pm 0.03^{\circ}$. This is regarded as a reference for joint angle estimated by $A P C A P$ and $M O C A P$ methods.

Three accelerometers are mounted on the articulated arm, one at each segment. The accelerometers are positioned at the distance $d_{1}=d_{2}=d_{3}=0.2 \mathrm{~m}$ from the center of the joint (Fig. 1b). A fourth accelerometer is mounted to the mobile platform. The tri-axial accelerometers used are ADXL362 (Analog Devices, Inc., Norwood, MA, USA), high end digital accelerometers with a resolution of \pm $0.04 \mathrm{~m} / \mathrm{s}^{2}$. The data acquisition is performed by dedicated microcontroller at a frequency of $50 \mathrm{~Hz}$ and a low pass filter with a cutoff frequency of $4 \mathrm{~Hz}$ was applied to the data since we know that the human balance control system works at frequencies below $2 \mathrm{~Hz}$.

Three optical markers are fixed to the articulated arm at each segment (Fig. 2). A fourth marker is attached to the platform. The markers' 3D trajectories are measured by a motion capture system composed of 3 infrared cameras CODAMOTION (Charnwood Dynamics Ltd, Rothley, UK), with performance measurement accuracy of $0.3 \mathrm{~mm}$ in $\mathrm{x}, \mathrm{y}, \mathrm{z}$ and a sampling rate of up to $800 \mathrm{~Hz}$. The motion capture system was clocked at $50 \mathrm{~Hz}$ to be consistent with the magnetic encoder's acquisition sampling rate. Note that, the data acquisition of the magnetic encoder sensors was made with a dedicated microcontroller through serial spi communication. The synchronization of the four acceleration sensors was made within their dedicated microcontroller. While the synchronization of the accelerometers with the encoders and the infrared camera is done within a PC connected to the sensors' microcontroller with high speed USB.

During testing, the platform oscillates with amplitude of $0.15 \mathrm{~m}$ and with three constant frequencies $0.3 \mathrm{~Hz}, 0.4 \mathrm{~Hz}$ and $0.5 \mathrm{~Hz}$. For each frequency, the tests were repeated 6 times.

\section{B. Results}

Results from the $A P C A P$ and $M O C A P$ methods are presented in Fig. 3. The measurements from the magnetic encoder are considered as a reference for the calculation of errors. The time window width of the $A P C A P$ algorithm is $N=99$. 
Table 1 summarizes the results of the estimated angles by APCAP method for all tests and for each of the three levels of perturbation frequencies with $A_{\max }$ being the maximum acceleration at the turn point, $e_{R M S}$ being the RMS error, and $r$ being the correlation coefficient.

The average angle error based on the $A P C A P$ method is of the same order of magnitude as those based on the MOCAP method. The average error for the three joints (hip, knee and ankle) is $0.47^{\circ}$ for APCAP method and $0.27^{\circ}$ for MOCAP method. This is an acceptable error for postural stability analysis. This error is much smaller than the variability of the maximum oscillation angle of subject between successive trials performed in the same condition.

Note a lower error from $0.12^{\circ}$ to $0.2^{\circ}$ for ankle compared to the other two joints. This result is primarily due to error propagation from the base to the top-end of the articulated arm. There is also a particularly high average error for the higher frequency of perturbation: it is due to the instability of the articulated arm in which the hip swing angle reached $37.6^{\circ}$. The maximum relative error of $5.4 \%$ is low and is of the same order of magnitude as that obtained with MOCAP method which is $3.0 \%$.

\section{Evaluation ON A SUBJECT}

In this section, we will evaluate the posture stability of a subject subjected to dynamic perturbations. We will compare joint angles estimated by $A P C A P$ method with those of $M O C A P$ method as well those from biomechanical simulation software LifeMOD (LM, LifeModeler, Inc., California, USA).

\section{A. Experimental conditions and method description}

As in section III, the dynamic perturbations are created by the same omnidirectional mobile platform on which a healthy subject is standing. The subject's height and weight were $1.65 \mathrm{~m}$ and $65 \mathrm{~kg}$ respectively. 
Three accelerometers are attached respectively to the shank, thigh and trunk with elastic belts (Fig. 4). Once attached, we measured their distance $d_{1}=0.28 \mathrm{~m}, d_{2}=0.24 \mathrm{~m}$ and $d_{3}=0.27 \mathrm{~m}$ relative to the center of rotation of their respective joints. Their axis $x$ is oriented parallel to the sagittal plane and orthogonal to the longitudinal axis of each segment. The accelerometer orientation is not accurate as it depends on segment shape. A fourth accelerometer is installed on the platform.

Five optical markers are also attached to the subject, on the ankle, knee, hip, trunk and shoulder (Fig. 4). With this minimum configuration, the orientation of each of the three segments is determined by at least two markers (the position of the trunk is defined by three markers). A sixth optical marker is attached on the platform and to the side of the foot. Markers' 3D displacements are captured by the same motion caption system described above.

As with the evaluation with the articulated arm, the platform repeats the same oscillatory movement with amplitude of $0.15 \mathrm{~m}$ and a frequency from $0.3 \mathrm{~Hz}$ to $0.5 \mathrm{~Hz}$. The perturbation occurs along an axis oriented at $45^{\circ}$ with respect to the sagittal plane of the subject (Fig. 4). Perturbation at $45^{\circ}$ allows simultaneous evaluation of joint angles on the anterior-posterior and medio-lateral planes. For each frequency, the test is repeated 6 times. During the test, the subject keeps his eyes open, focusing on a target located at eye's height and $4 \mathrm{~m}$ away from him.

\section{A. Complete skeletal model in LifeMOD}

To compare and validate our results, we used the biomechanical simulation software LifeMOD (LM), a plug-in to Adams software (MSC Software, Newport Beach, USA). LM is world's most widely used multibody dynamics software, it allows biomechanical simulation of a full 3D musculoskeletal human model.

In our test, the skeleton model created in LM is composed of 19 segments and 18 joints. Some segment consists of several bones and viewed as a rigid segment, such as the foot segment. In order to match the model created in LM to the tri-articulated planar model, we only kept motion for the ankle, 
knee and hip joints, and blocked all the other joints. We have limited the movement of the knee joint in the sagittal plane and those of the hip and ankle in frontal and sagittal planes. The model is shown standing on a movable platform (Fig. 5).

In LM, the movement of the skeletal model is driven by "motion agent". Each "motion agent" is controlled by the optical marker through an elastic virtual link. Therefore the "motion agent" is a flexible system that reduces path following error caused mainly by the geometrical differences between the virtual model and the real person, the positioning errors of the markers on the real person, and the markers sliding on the skin.

\section{B. Anterior-posterior results}

In this section we compare the estimated joint angle from $M O C A P$ method (considered as reference), APCAP method and the LM method performed in the sagittal plane. Figure 6a show results of the three joint angles.

As illustrated by Fig. $6 \mathrm{~b}$ and Table 2, the average error of $A P C A P$ method is equal to $0.45^{\circ}$ for all joints and all perturbations frequencies, which is very close to $0.43^{\circ}$ from $\mathrm{LM}$. The average error of the ankle is smaller than the other two joints which are in concordance with the results obtained in the previous experiment with articulated arm.

Details of the results calculated by $A P C A P$ method are given in Table 2 . They correspond to the mean values of 6 trials for each joint and each perturbation frequency. The maximum relative error is $3.76 \%$ for a range of motion of $11.3^{\circ}$. This error is acceptable and comparable to $4.67 \%$ obtained by LM. This is an acceptable error for the human stability analysis application, because it is much smaller than the variability of the maximum or minimum oscillation angle of subject between successive trials done in the same condition. 


\section{Medio-lateral results}

In this section we compare the estimated joint angle obtained from $A P C A P$ and LM methods performed in the frontal plane to those from the MOCAP method (considered as reference) see Fig. 7a. The observed errors with $A P C A P$ algorithm are on the order of $0.56^{\circ}$, slightly less than the $0.61^{\circ}$ error form LM.

Details of the results for each joint and perturbation frequency are given in Table 3 . The maximum relative error is $10.75 \%$ for a range of motion of $9.4^{\circ}$. This error is higher than that estimated in the sagittal plane, and can be explained by the effective model simplification. In fact, in the APCAP model we have considered only one serial chain of 3 segments without taking into account the parallel kinematic structure that represents both legs of humans. The higher error can also be explained by the attachment position errors which are not apparent in large motions (such as flexion-extension) but they may appear more in smaller motions (such abduction-adduction) of the joints. However, as explained in anterior-posterior experiment, our results are still acceptable for the analysis of human balance.

\section{Discussion}

The overall objective of this investigation is to provide clinicians with a simple and accurate method for posture stability analysis. Experimental results demonstrate the viability of our $A P C A P$ method for estimating the ankle, knee, and hip joint angles with sufficient accuracy, thus making it an excellent low cost method.

Additional experiments, not discussed here, were conducted to determine the effect of the accelerometer location on the body. We found that, positioning the accelerometer within $10 \mathrm{~cm}$ from the joint center did not change the accuracy. Also a $1 \mathrm{~cm}$ measurement error of the vertical distance of the accelerometer to the ground has a negligible effect.

The accelerometer drift has no effect on the joint angle estimation because the APCAP algorithm is 
based on equation (4) where experimentally the products $\mathrm{a}_{\mathrm{xi}}^{\mathrm{d}} \mathrm{c} \alpha \mathrm{i}$ and $\mathrm{a}_{\mathrm{zi}}^{\mathrm{d}} \mathrm{c} \beta_{\mathrm{i}}$ are small compared to the elements of the diagonal of Ei then Di matrix elements have a negligible effect on the convergence of the algorithm. This assertion was confirmed by our experiment comparing accelerometer-based method with encoder and optical marker based method.

The APCAP algorithm assumes the initial angle equal to zero and the accelerometer are aligned with body segment. Indeed the orientations of the accelerometer depend on the shape of subject's body segment and are very hard to measure them. The $A P C A P$ estimated angles are then inaccurate in term of absolute value and only the relative angle or angle variations are accurate. Since almost all parameters commonly used to evaluate postural stability are calculated from the relative motion of center pressure (Chaudhry, 2004), the relative joint motion is sufficient. A separate experiment, not described here, shows that changing the orientation of accelerometer mounted on the articulated arm had no significant effect on the accuracy of estimating the joint angle.

Finally, analyzing stability from the joint angle point of view, gives a significant advantage to the commonly used center of pressure stabilogram. It allows an evaluation of the subject posture stability strategy, and hip versus ankle strategy, a critical and important difference in elderly population.

\section{Conclusion}

This paper presented a method for estimating the $3 \mathrm{D}$ posture of a human subject submitted to a dynamic perturbation. The posture is estimated from four tri-axial accelerometers, three of which are attached to the subjects. The perturbation is created by an omnidirectional mobile platform. The principle of the method is presented by a model of a four segments inverted pendulum that simulates the foot, shank, thigh and trunk with three joints representing the ankle, knee and hip of a subject. Two experiments are conducted to validate this method. The first experiment uses an articulated mechanical arm with 3 types of sensor (magnetic encoder, optical marker, and accelerometer). The second 
experiment is performed on a healthy subject standing on platform. For evaluation, the estimation errors in terms of RMS are $0.45^{\circ}$ in the sagittal plane and $0.56^{\circ}$ in the frontal plane. These errors are comparable to those obtained by a very expensive optical motion capture system alone or coupled with and advanced, state of the art biomechanical simulation software. The small error obtained in the joint angle estimation makes our $A P C A P$ method a simple and affordable low cost solution for posture stability analysis. 


\section{Conflict of Interest Statement}

This work was supported by the company ASSISTMOV founded by Mourad BOUZIT (the corresponding author) and BPIFRANCE (Government agency providing assistance and financial support to French innovation).

\section{Acknowledgements}

The authors wish to acknowledge the support of the French company ASSISTMOV, the robotic laboratory ISIR at University UPMC and the hospital Rothschild in Paris.

\section{References}

Caroselli, A., Bagalà, F., Cappello, A., 2013. Quasi-Real Time Estimation of Angular Kinematics Using Single-Axis Accelerometers. Sensors 13(1), 918-937.

Chaudhry, H., Findley, T., Quigley, K.S., Bukiet, B., Ji, Z., 2004. Measures of postural stability. Journal of Rehabilitation Research and Development 41, 713-720.

Craig, J.J., 1989. Introduction to robotics (Vol. 7). Reading, MA: Addison-Wesley.

Dejnabadi, H., Jolles, B.M., Aminian, K., 2005. A new approach to accurate measurement of uniaxial joint angles based on a combination of accelerometers and gyroscopes. Biomedical Engineering, IEEE Transactioins on 52(8), 1478-1484.

Drillis, R., Contini, R., 1966. Body segment parameters. Technical Report 1166.03, New York University, School of Engineering and Science, New York.

Faucher, N., Roger, M., Teillet, L., 2000. Gait disorders and falls in the elderly. Diagnostic orientation. In Rev Prat 50, pp. 1245-1251. [Article in French]. 
Fong, D.T.P., Chan, Y.Y., 2010. The use of wearable inertial motion sensors in human lower limb biomechanics studies: A systematic review. Sensors 10(12), 11556-11565.

Halpern, P., Siebzehner, M.I., Aladgem, D., Sorkine, P., Bechar, R., 2005. Non-collision injuries in public buses: a national survey of a neglected problem. Emergency medicine journal 22(2), 108110.

Heyn, A., Mayagoitia, R.E., Nene, A.V., Veltink, P.H., 1996. The kinematics of the swing phase obtained from accelerometer and gyroscope measurements. In Engineering in Medicine and Biology Society, 1996. Bridging Disciplines for Biomedicine. Proceedings of the 18th Annual International Conference of the IEEE Vol. 2, pp. 463-464.

Liu, K., Liu, T., Shibata, K., Inoue, Y., Zheng, R., 2009. Novel approach to ambulatory assessment of human segmental orientation on a wearable sensor system. Journal of biomechanics 42(16), 2747.

Ma, J., Kharboutly, H., Benali, A., Ben Amar, F., Bouzit, M., 2014. Design of Omnidirectional Mobile Platform for Balance Analysis. IEEE/ASME Trans. Mechatronics, 19(6), pp. 1872-1881.

O’Donovan, K.J., Kamnik, R., O’Keeffe, D.T., Lyons, G.M., 2007. An inertial and magnetic sensor based technique for joint angle measurement. Journal of biomechanics 40(12), 2604-2611.

Pereira, M.S., 2006. Structural Crashworthiness of Railway Vehicles. In 7th World Congress of Rail Research, Montreal, Canada.

Tadano, S., Takeda, R., Miyagawa, H., 2013. Three dimensional gait analysis using wearable acceleration and gyro sensors based on quaternion calculations. Sensors 13(7), 9321-9343.

Takeda, R., Tadano, S., Natorigawa, A., Todoh, M., Yoshinari, S., 2009. Gait posture estimation using wearable acceleration and gyro sensors. Journal of Biomechanics 42 (15), 2486-2494.

Thomas, L.H., 1949. Elliptic Problems in Linear Differential Equations over a Network. Watson Science Computer Laboratory Report. Columbia University: New York, NY, USA.

Willemsen, A.T.M., Van Alste, J.A., Boom, H.B.K., 1990. Real-time gait assessment utilizing a new way of accelerometry. Journal of Biomechanics 23(8), 859-863. 
Williamson, R., Andrews, B.J., 2001. Detecting absolute human knee angle and angular velocity using accelerometers and rate gyroscopes. Medical and Biological Engineering and Computing 39(3), 294-302. 


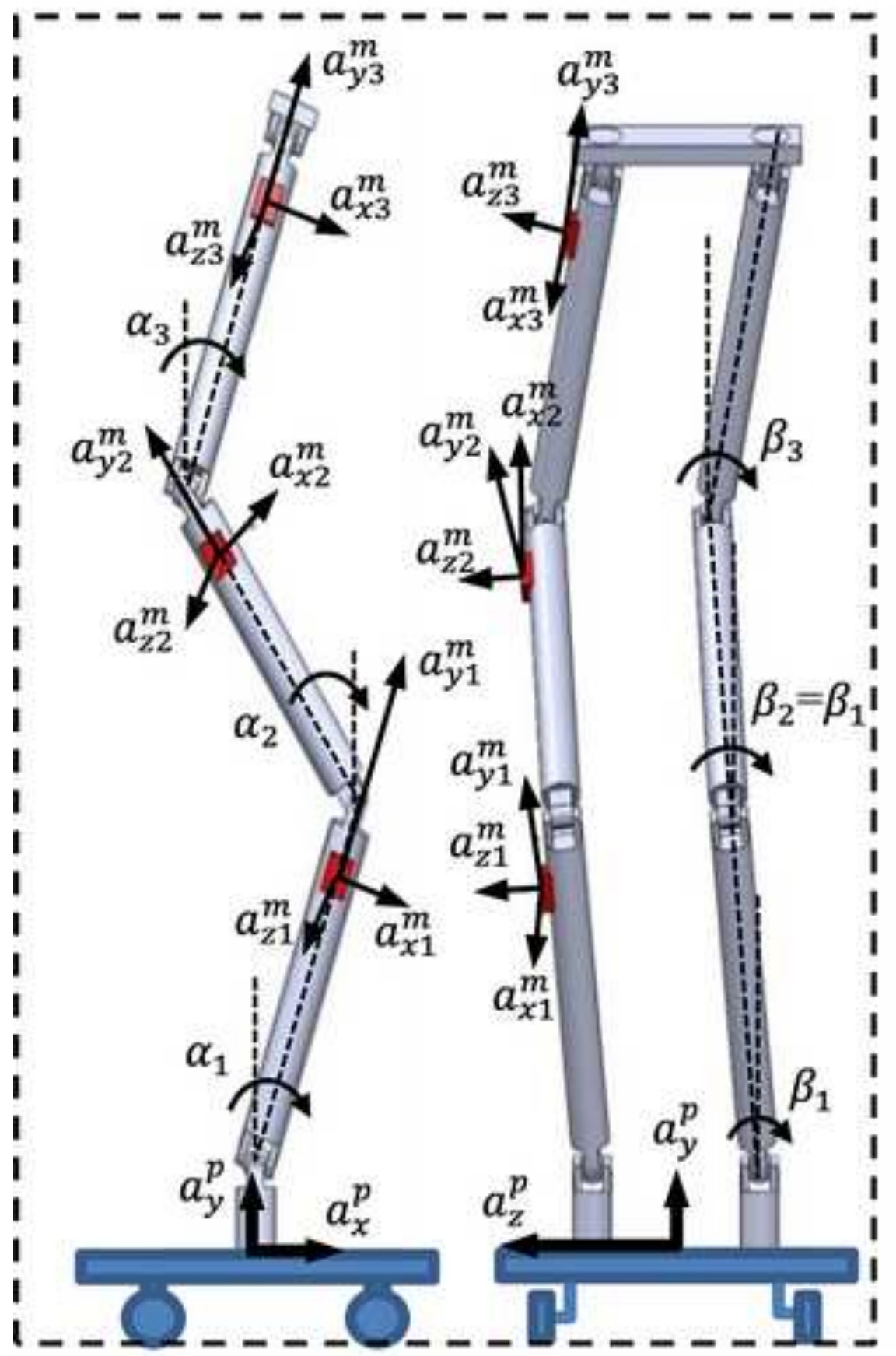

(a)

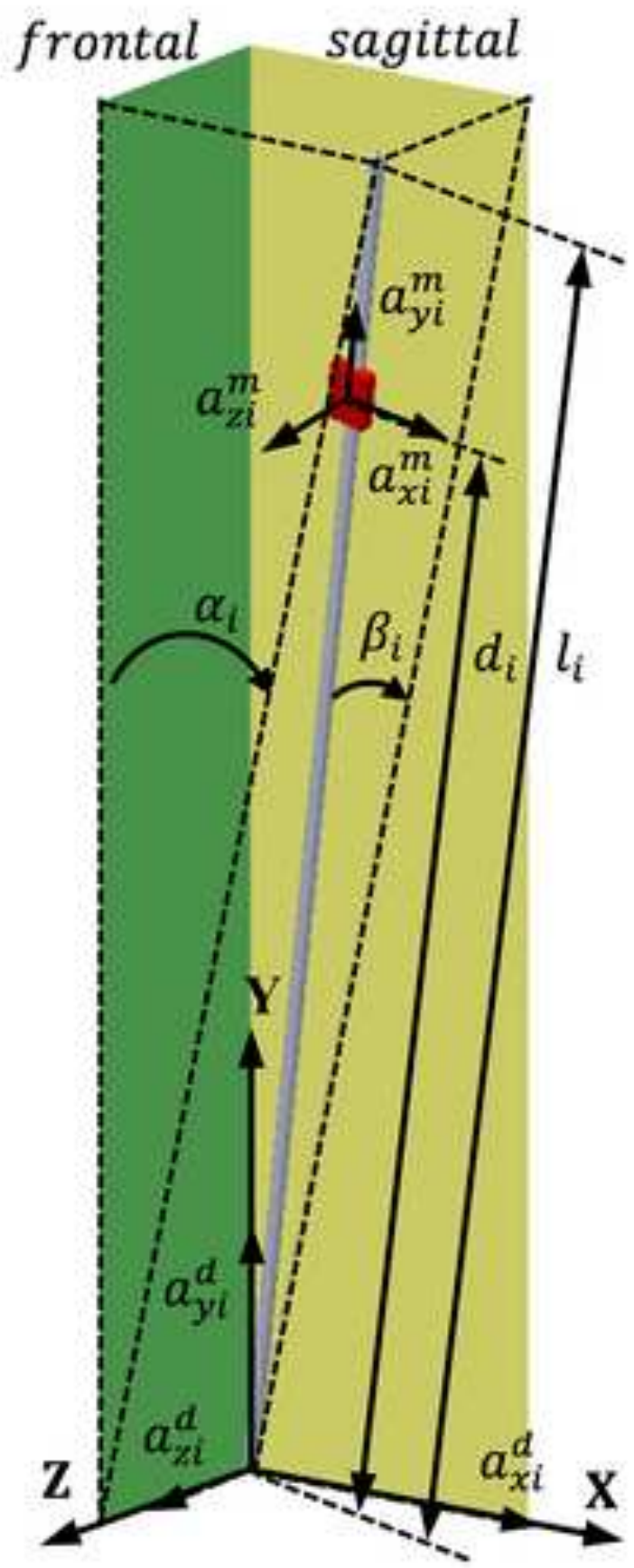

(b) 


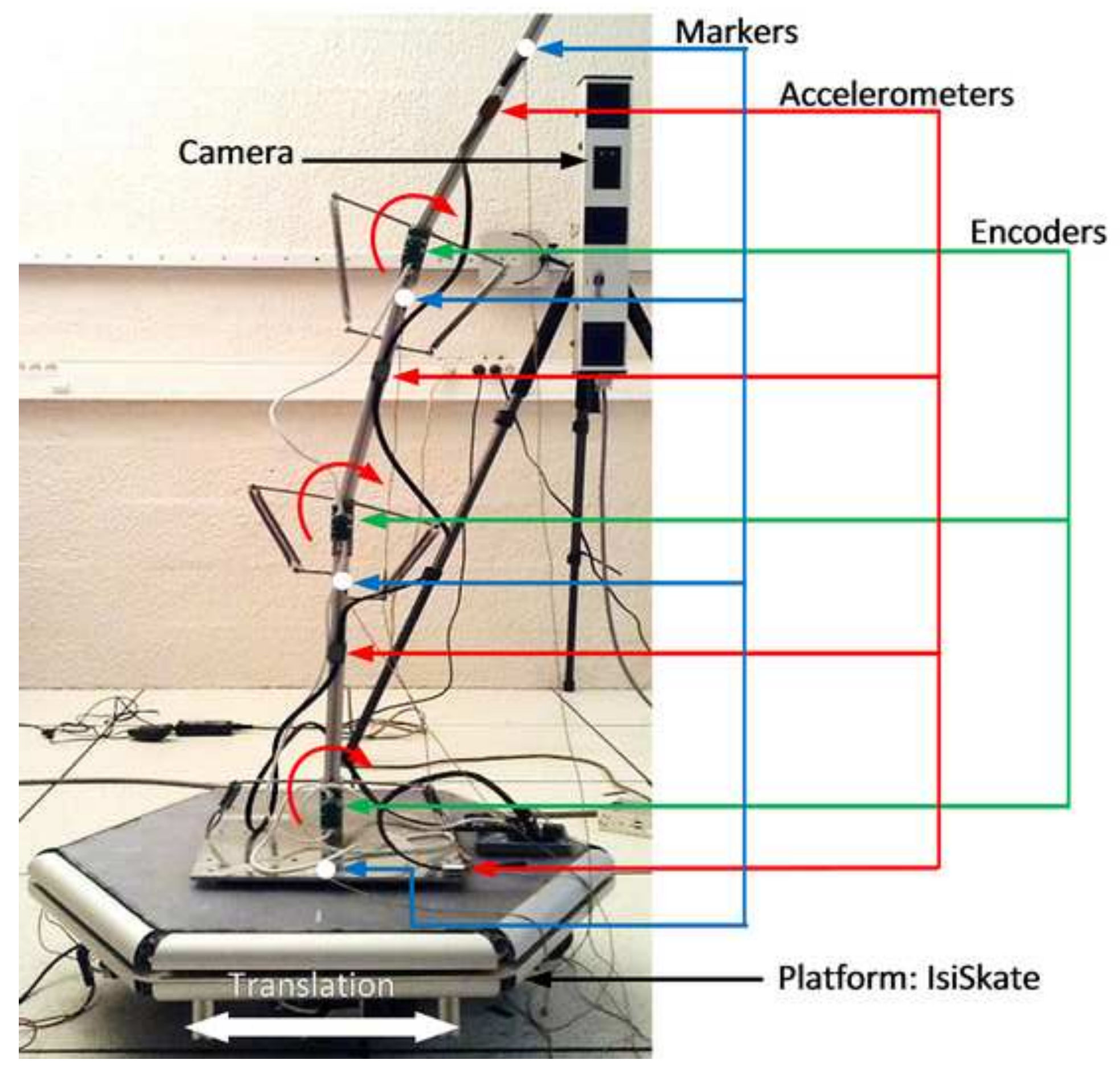



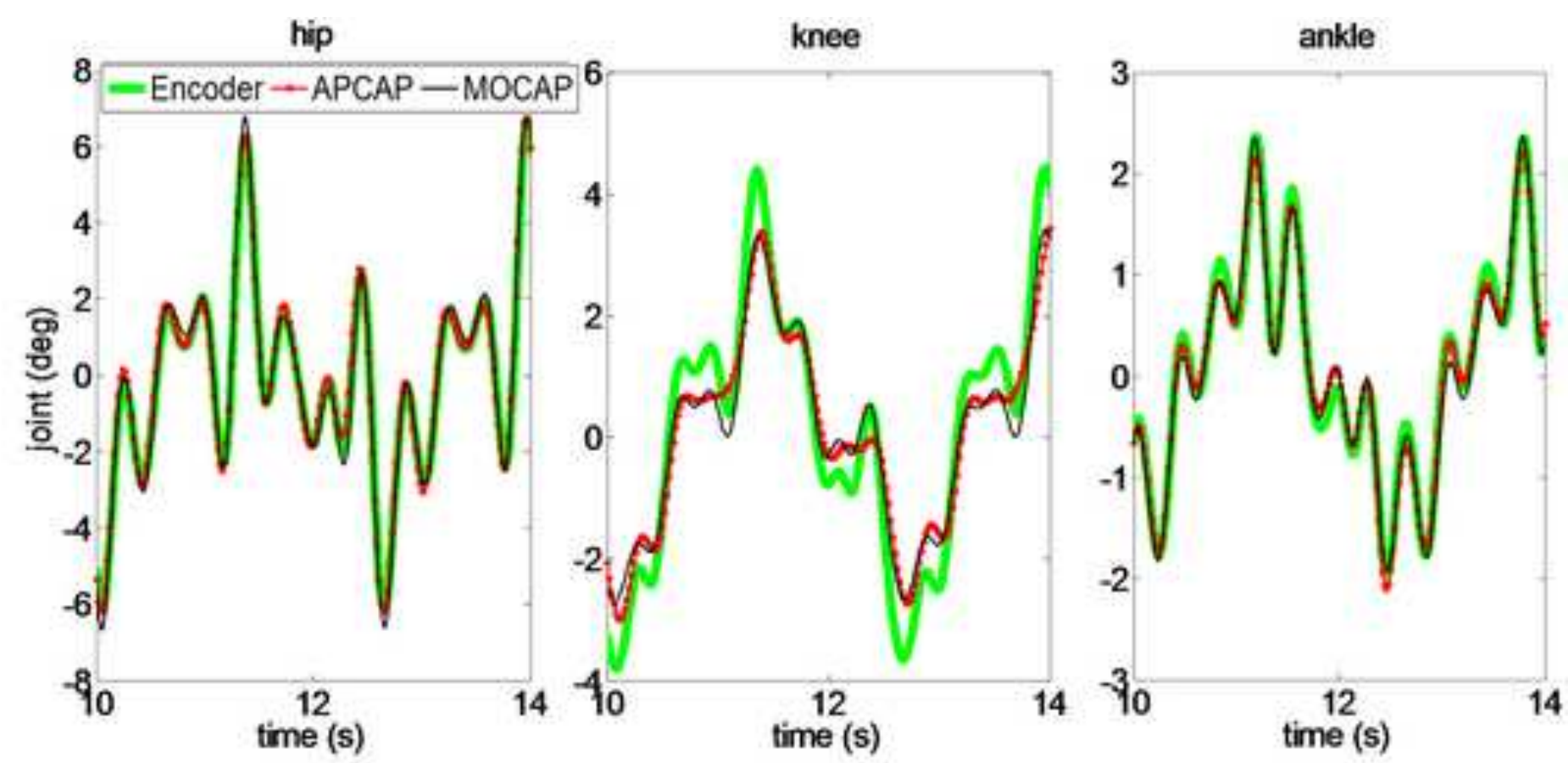

(a)
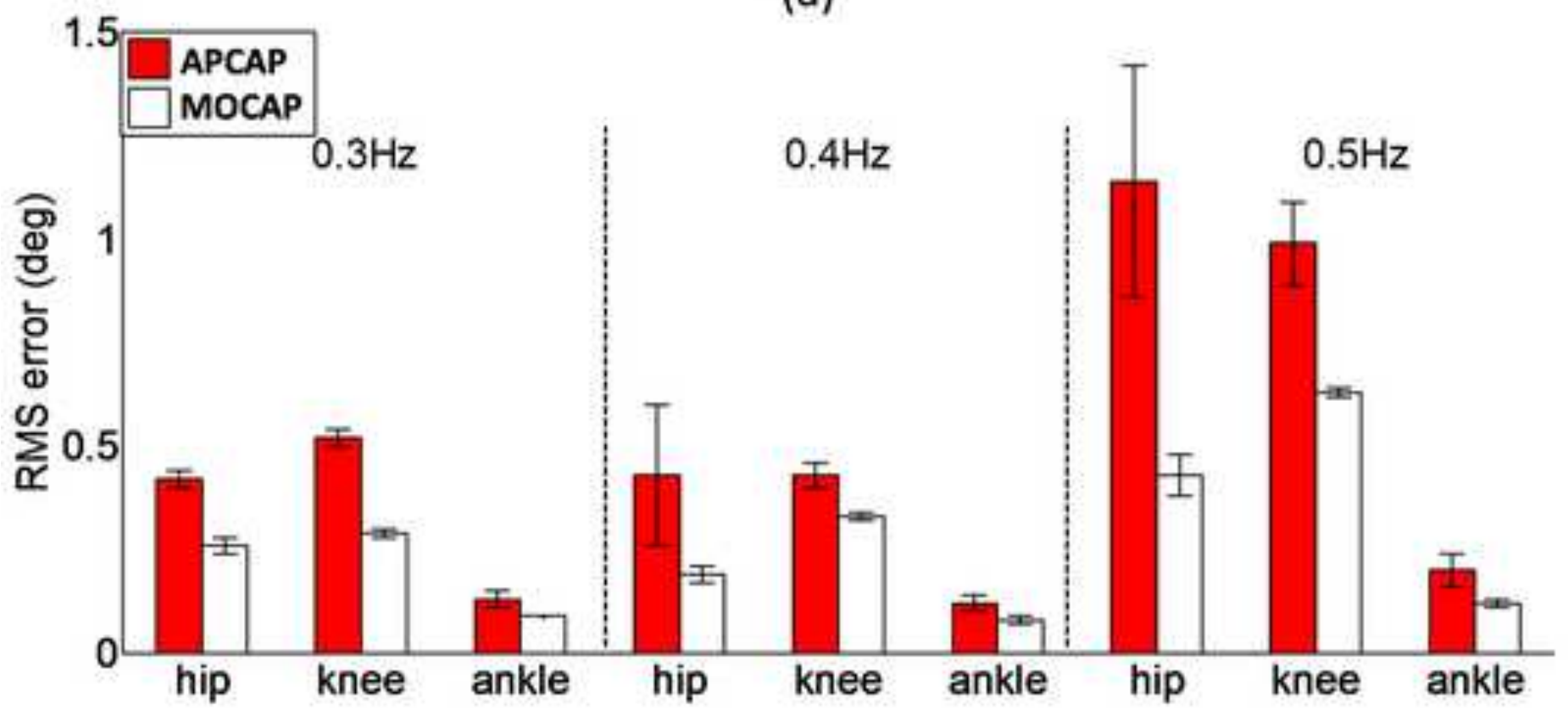

(b) 
Click here to download high resolution image

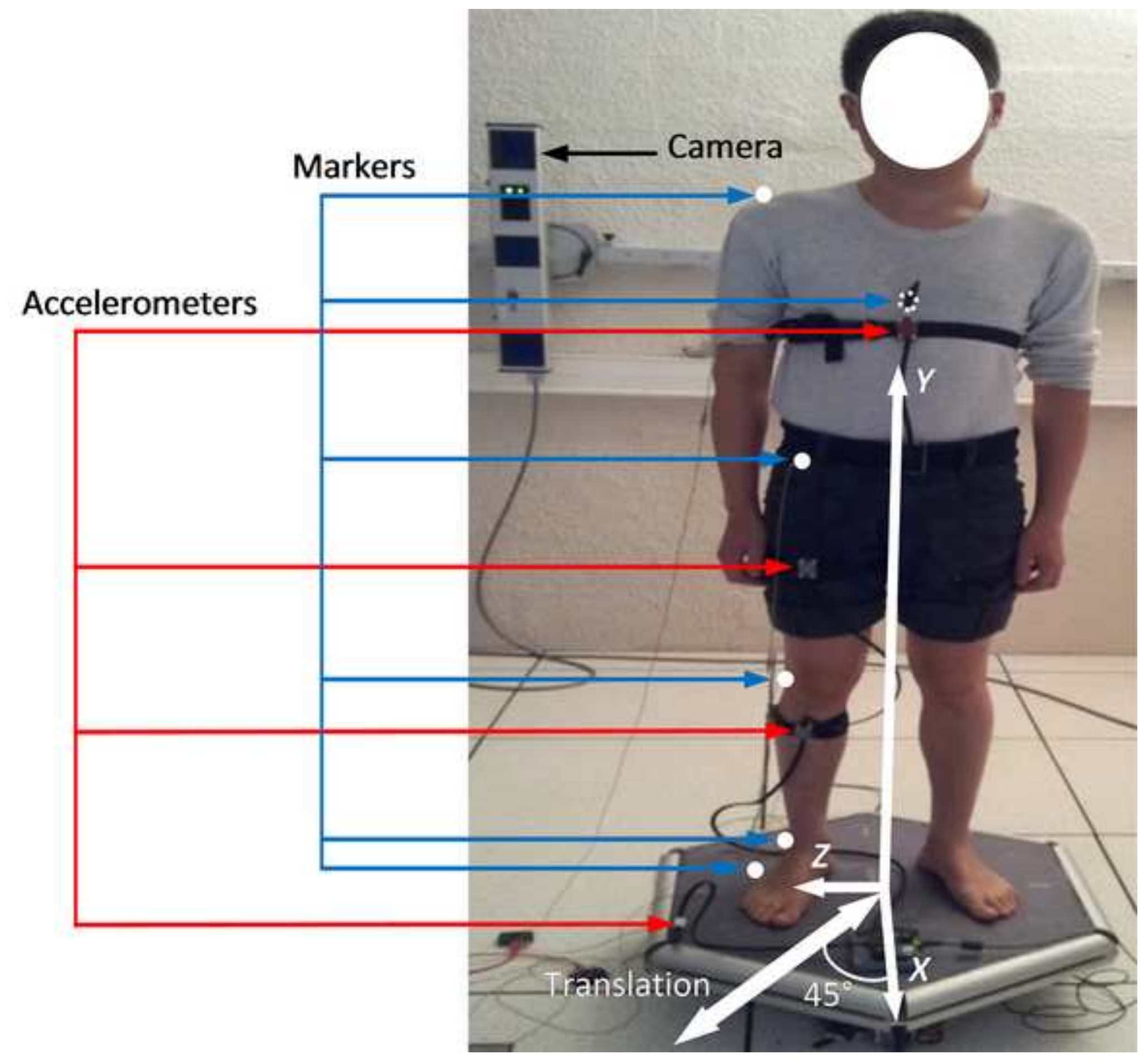




\section{Motion agent}

\section{Anthropometric Trajectories measurements of markers}

Joint
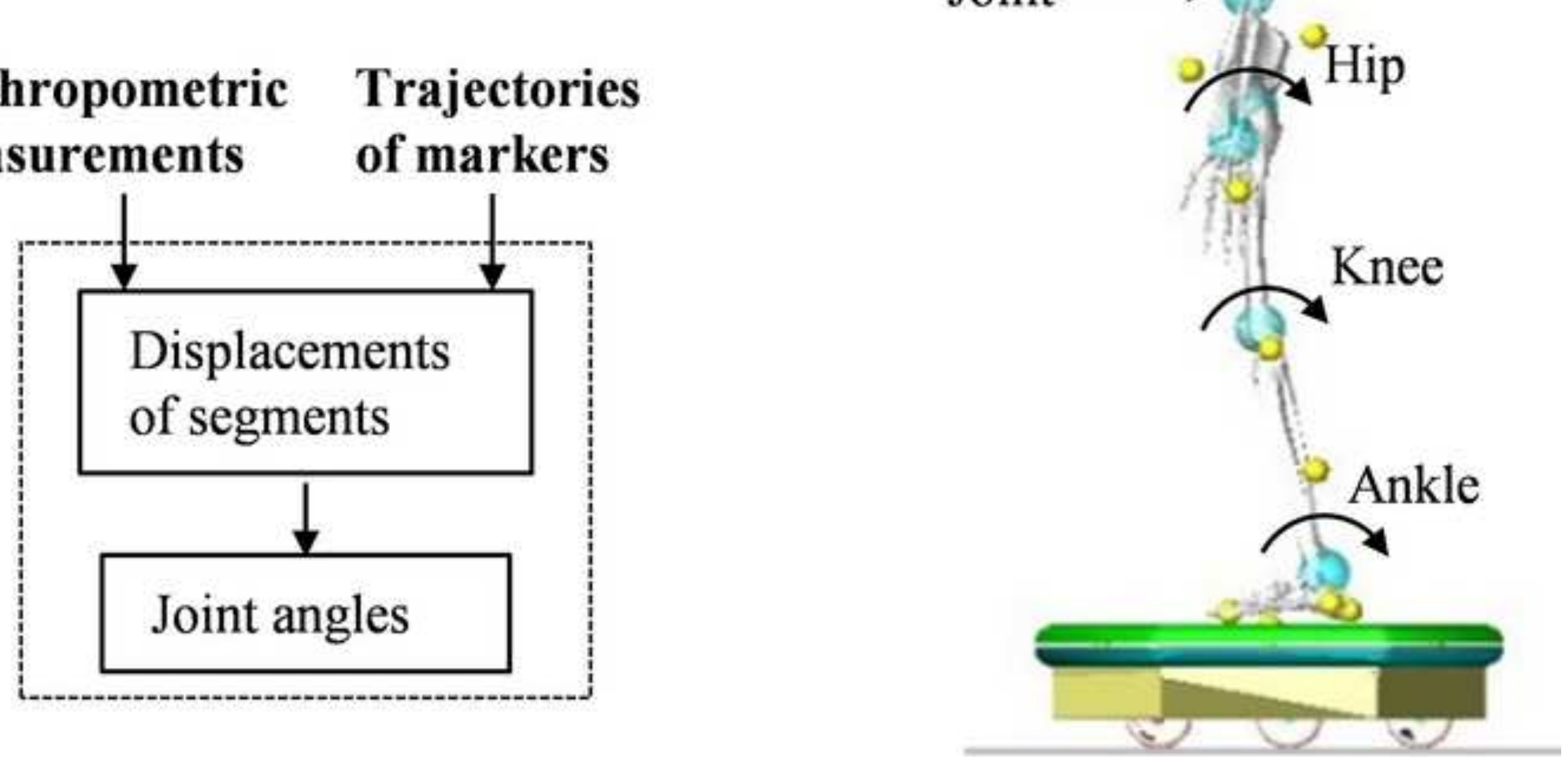

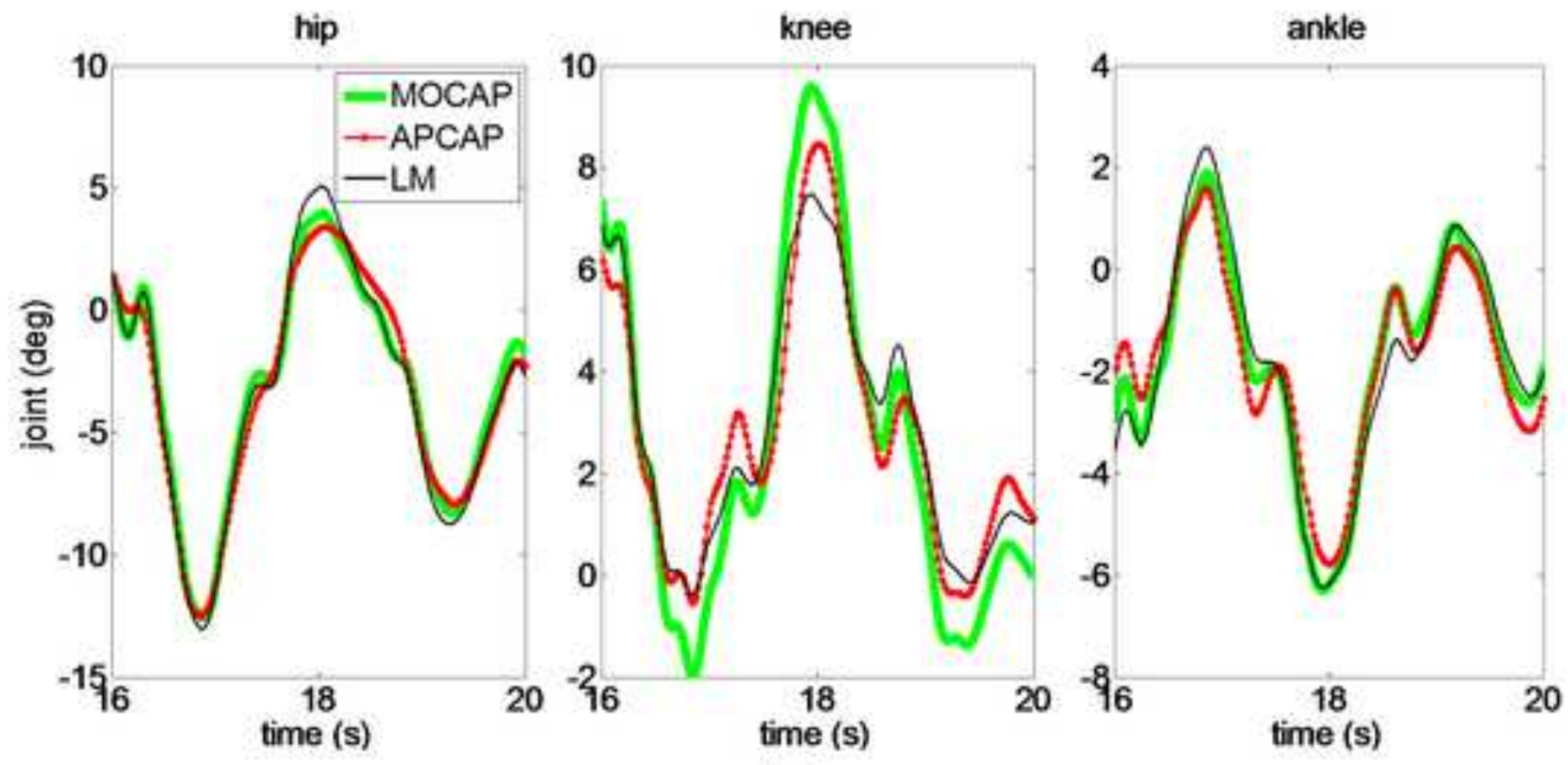

(a)

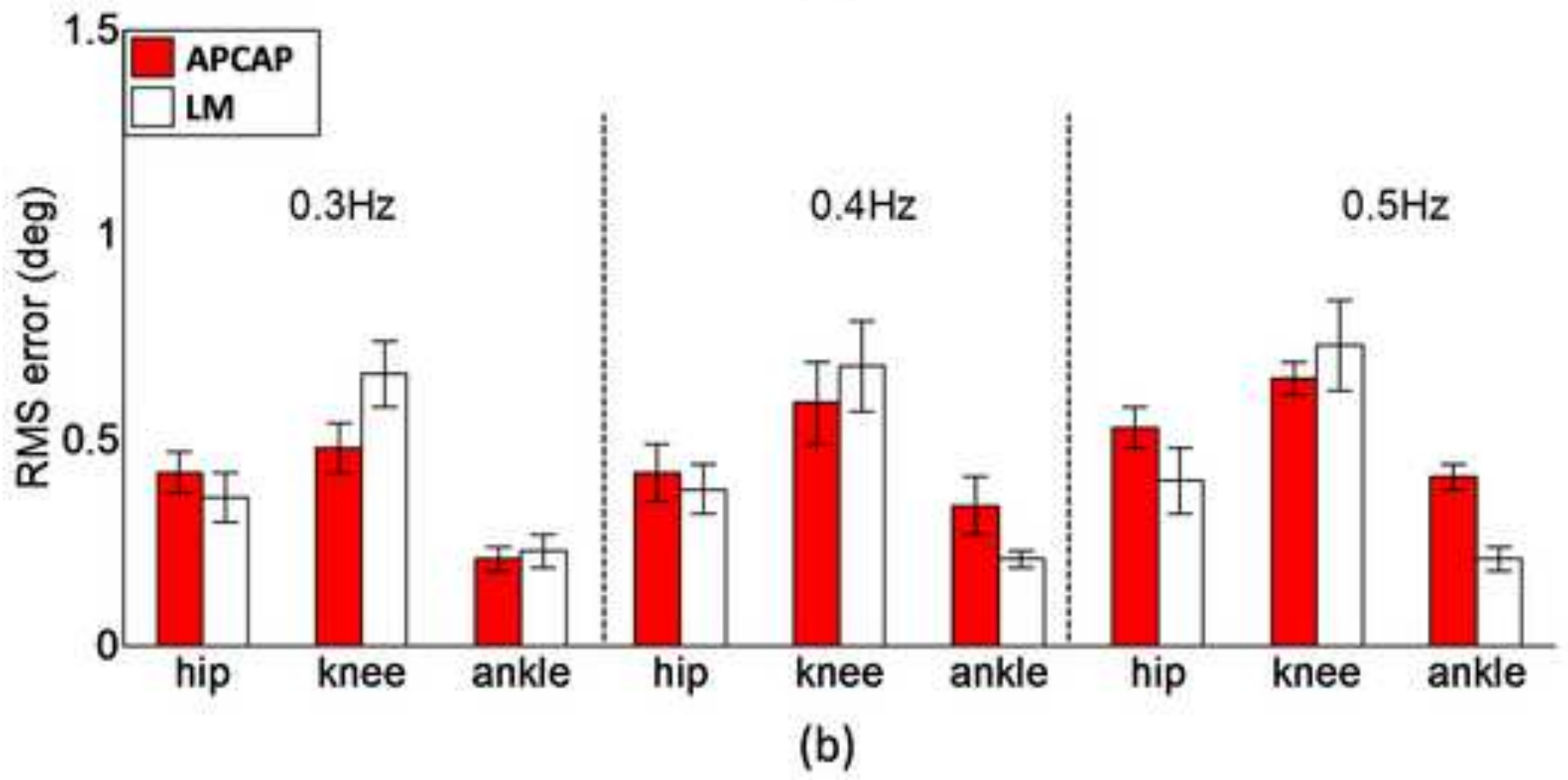



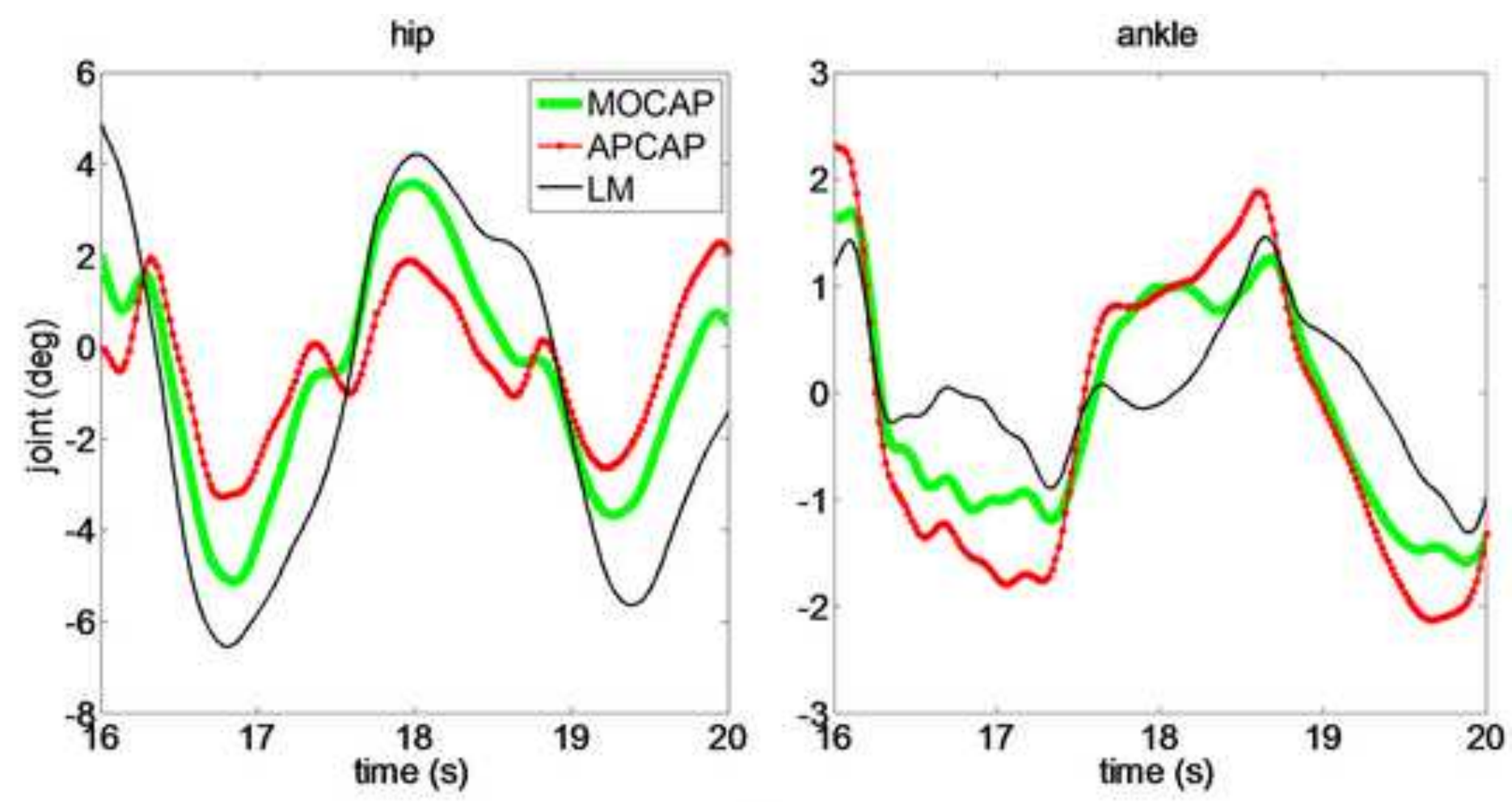

(a)

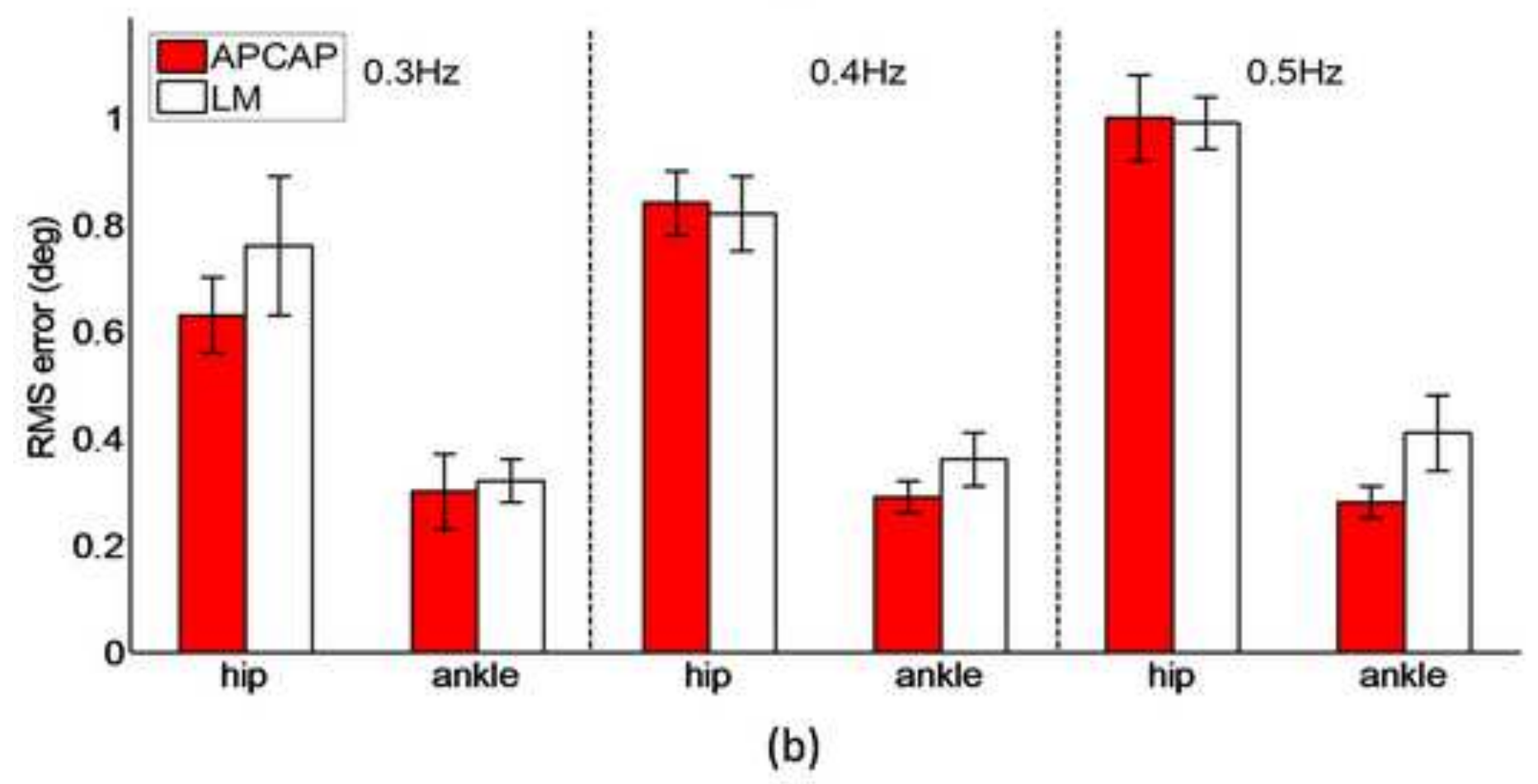


Table 1

\begin{tabular}{ccccccc}
\hline \hline $\boldsymbol{A}_{\max }\left(\boldsymbol{m} / \mathbf{s}^{\mathbf{2}}\right)$ & Joint & $\boldsymbol{e}_{\boldsymbol{R M S}}\left(^{\circ}\right)$ & $\boldsymbol{r}$ & $\boldsymbol{e \%}$ & $\boldsymbol{e}_{\max }\left(^{\circ}\right)$ & $\boldsymbol{R O M}\left(^{\circ}\right)$ \\
\hline \multirow{3}{3.43}{} & hip & 0.42 & 0.98 & 1.98 & 2.79 & 21.31 \\
$(\mathbf{f}=\mathbf{0 . 3 H z})$ & knee & 0.52 & 0.93 & 5.38 & 2.64 & 9.61 \\
& ankle & 0.13 & 0.99 & 2.27 & 1.05 & 5.69 \\
\hline \multirow{2}{*}{$\mathbf{4 . 7 4}$} & hip & 0.43 & 0.98 & 1.96 & 5.61 & 21.37 \\
$(\mathbf{f}=\mathbf{0 . 4 H z})$ & knee & 0.43 & 0.97 & 3.46 & 2.67 & 12.59 \\
& ankle & 0.12 & 0.99 & 1.71 & 1.03 & 6.78 \\
\hline \multirow{2}{*}{$\mathbf{5 . 2 8}$} & hip & 1.14 & 0.97 & 3.04 & 8.21 & 37.59 \\
$(\mathbf{f}=\mathbf{0 . 5 H z})$ & knee & 0.99 & 0.97 & 3.77 & 5.57 & 26.18 \\
& ankle & 0.20 & 0.99 & 1.63 & 1.28 & 12.17 \\
\hline \hline
\end{tabular}


Table 2

\begin{tabular}{|c|c|c|c|c|c|c|}
\hline$A_{\max }\left(m / s^{2}\right)$ & Joint & $e_{R M S}\left(^{\circ}\right)$ & $\boldsymbol{r}$ & $e \%$ & $e_{\max }\left(^{\circ}\right)$ & $\operatorname{ROM}\left(^{\circ}\right)$ \\
\hline \multirow{3}{*}{$\begin{array}{c}3.43 \\
(f=0.3 H z)\end{array}$} & hip & 0.42 & 0.96 & 3.67 & 2.29 & 11.93 \\
\hline & knee & 0.48 & 0.99 & 3.41 & 2.62 & 14.05 \\
\hline & ankle & 0.21 & 0.99 & 2.45 & 1.41 & 8.72 \\
\hline \multirow{3}{*}{$\begin{array}{c}4.74 \\
(f=0.4 \mathrm{~Hz})\end{array}$} & hip & 0.42 & 0.98 & 3.00 & 2.06 & 14.88 \\
\hline & knee & 0.59 & 0.99 & 3.48 & 3.16 & 16.78 \\
\hline & ankle & 0.34 & 0.98 & 3.42 & 2.09 & 9.94 \\
\hline \multirow{3}{*}{$\begin{array}{c}5.28 \\
(f=0.5 H z)\end{array}$} & hip & 0.53 & 0.98 & 3.12 & 2.76 & 17.39 \\
\hline & knee & 0.65 & 0.99 & 3.35 & 3.50 & 19.87 \\
\hline & ankle & 0.41 & 0.98 & 3.76 & 2.24 & 11.26 \\
\hline \multicolumn{2}{|c|}{ Mean } & 0.45 & 0.98 & 3.30 & & \\
\hline
\end{tabular}


Table 3

\begin{tabular}{ccccccc}
\hline \hline $\boldsymbol{A}_{\max }\left(\boldsymbol{m} / \mathbf{s}^{2}\right)$ & Joint & $\boldsymbol{e}_{\boldsymbol{R M S}}\left({ }^{\circ}\right)$ & $\boldsymbol{r}$ & $\boldsymbol{e} \%$ & $\boldsymbol{e}_{\max }\left({ }^{\circ}\right)$ & $\boldsymbol{R O M}\left(^{\circ}\right)$ \\
\hline $\mathbf{3 . 4 3}$ & hip & 0.63 & 0.61 & 9.36 & 2.69 & 7.05 \\
$(\mathbf{f}=\mathbf{0 . 3 H z})$ & ankle & 0.30 & 0.90 & 8.18 & 1.43 & 3.83 \\
\hline $\mathbf{4 . 7 4}$ & hip & 0.84 & 0.49 & 10.74 & 3.33 & 8.35 \\
$(\mathbf{f}=\mathbf{0 . 4 H z})$ & ankle & 0.29 & 0.95 & 6.88 & 1.35 & 4.23 \\
\hline $\mathbf{5 . 2 8}$ & hip & 1.00 & 0.53 & 10.75 & 4.07 & 9.41 \\
$(\mathbf{f}=\mathbf{0 . 5 H z})$ & ankle & 0.28 & 0.96 & 5.36 & 1.31 & 5.09 \\
\hline Mean & & $\mathbf{0 . 5 6}$ & $\mathbf{0 . 7 4}$ & $\mathbf{8 . 5 5}$ & & \\
\hline \hline
\end{tabular}

Mean 